\title{
Effects of sample size on neutral detergent fiber digestibility of triticale forages using the Ankom Daisy" Incubator system
}

\author{
W. K. Coblentz, ${ }^{* 1}$ M. S. Akins, ${ }^{2}$ R. K. Ogden, ${ }^{1}$ L. M. Bauman, ${ }^{3}$ and A. J. Stammer ${ }^{3}$ \\ ${ }^{1}$ USDA-Agricultural Research Service, US Dairy Forage Research Center, Marshfield, WI 54449 \\ ${ }^{2}$ Department of Dairy Science, University of Wisconsin, Madison 53706 \\ ${ }^{3}$ University of Wisconsin Soil and Forage Laboratory, Marshfield 54449
}

\section{ABSTRACT}

Accurate and precise determinations of fiber digestibility are essential for proper diet formulation for dairy cows. Our objectives were 3 -fold: (1) regress in vitro neutral detergent fiber digestibility (NDFD) values from 48 triticale forages determined at multiple endpoints ranging from 12 to $240 \mathrm{~h}$ with Ankom Daisy ${ }^{\mathrm{II}}$ Incubator system (Ankom Technology Corp., Macedon, NY) methods using 0.25- or 0.50-g sample sizes on concentrations of fiber-related analytes or growth stage; (2) directly compare NDFD values determined with 0.25 - or $0.50-\mathrm{g}$ sample sizes by Ankom methods after 12-, 24-, 30-, 48-, 144-, or 240-h incubations; and (3) compare NDFD values determined by Ankom methods after 30 and $48 \mathrm{~h}$ of incubation with those determined by traditional sealed-tube procedures obtained from a commercial laboratory. Generally, plant growth stage, which was quantified with a linear model suitable for serving as an independent regression variable, proved to be a better predictor variable for NDFD than neutral detergent fiber or acid detergent lignin. For direct comparisons of 0.25- and 0.50-g sample sizes using Ankom methods, the regression relationship for a 30-h incubation was explained by a linear model $[\mathrm{Y}=$ $1.206 \mathrm{x}-1.1$; coefficient of determination $\left(\mathrm{R}^{2}\right)=0.933$, in which the slope differed from unity, but the intercept did not differ from 0 . After a 48-h incubation, a linear model $\left(\mathrm{Y}=1.014 \mathrm{x}+7.1 ; \mathrm{R}^{2}=0.964\right)$ indicated that the slope did not differ from unity, but the intercept was $>0$. A linear regression $\left(\mathrm{Y}=1.040 \mathrm{x}-1.8 ; \mathrm{R}^{2}\right.$ $=0.861$ ) of the $30-\mathrm{h}$ incubation results obtained by Ankom methods using the 0.25 -g sample size on those from the commercial laboratory indicated the slope and intercept did not differ from unity or 0 , respectively. A similar relationship was obtained from the 48-h incubation $\left(\mathrm{Y}=1.021 \mathrm{x}-3.4 ; \mathrm{R}^{2}=0.866\right)$. Relationships

Received March 25, 2019.

Accepted April 24, 2019.

*Corresponding author: wayne.coblentz@ars.usda.gov were poorer when the 0.50 -g sample size was used by Ankom methods, particularly for the 30 -h incubation, where the slope (0.824) was less than unity. Generally, NDFD values were greater for the 0.25 -g sample size by Ankom methods, especially with 24-, 30-, and 48-h incubation times, and agreement with traditional sealed-tube methods was improved with the smaller sample size. Synchronization of results between Ankom and traditional methods needs to be further verified across a wider range of forages and harvest/preservation methods before definitive recommendations can be made.

Key words: in vitro neutral detergent fiber digestibility, sample size, triticale

\section{INTRODUCTION}

Over the past $20 \mathrm{yr}$ or more, it has become common for in vitro digestion procedures to use fiber bags and large collective incubation vessels as developed by Ankom Technology Corp. (Macedon, NY) for the Daisy ${ }^{\text {II }}$ Incubator System, thereby allowing digestion of approximately 24 samples within the same fermentation vessel or jar. With this technique (Ankom), individual forage or other feedstuff samples are sealed within their own dedicated filter bag, but are incubated in a large fermentation jar with other samples that may, or may not, be similar with respect to species, composition, or a host of other factors. These procedures contrast sharply with those traditional methods that feature an unrestrained sample incubated within a small sealed tube or flask dedicated to that specific sample (STD; Tilley and Terry, 1963; Goering and Van Soest, 1970). Several studies (Holden, 1999; Vogel et al., 1999; Wilman and Adesogan, 2000) have compared these contrasting techniques, generally concluding that the filter bag technique gives acceptable results for in vitro DM digestibility of forages and feedstuffs that were comparable with those produced in small tubes or flasks. Vogel et al. (1999) compared the in vitro DM disappearance of 23 smooth bromegrass (Bromus inermis Leyss.), switch- 
grass (Panicum virgatum L.), and forage sorghum [Sorghum bicolor (L.) Moench] forages by Ankom and STD methods, and found within-species differences between methodologies only for smooth bromegrass. However, that study concluded that in vitro DM digestibilities were ranked in the same relative order, regardless of method, and that the mean standard deviation for each forage was reduced with Ankom methods. Conversely, Wilman and Adesogan (2000) found that STD methods yielded better precision than Ankom methods for in vitro DM disappearance of Italian ryegrass (Lolium multiflorum Lam.) and alfalfa (Medicago sativa L.) forages. Furthermore, Holden (1999) found no differences in methodology when a wide variety of feedstuffs were incubated in a common jar by Ankom methods, compared with maintaining like or similar samples within a common incubation jar. Collectively, numerous studies have suggested that Ankom methodology offers clear advantages over STD techniques with respect to time efficiency and labor requirements, and generally may be more suitable for large numbers of samples (Holden, 1999; Vogel et al., 1999; Wilman and Adesogan, 2000; Ricci et al., 2009).

More recently, a major focus of forage analysis has been the estimation of neutral detergent fiber digestibility (NDFD), primarily from forage substrates. This has included single-point-in-time endpoints, such as those selected commonly at 30 or $48 \mathrm{~h}$, the most appropriate of which is intended to reflect the consequences of differences in passage kinetics from the rumen. In addition, research has increasingly focused on NDFD at extended time intervals, such as $240 \mathrm{~h}$, that are required for direct estimation of indigestible NDF, which is essential for estimating the kinetics of NDF degradation by more complex models that include fast, slow, and indigestible NDF pools (Raffrenato and Van Amburgh, 2010; Grant, 2015; Mertens, 2016; Raffrenato et al., 2019). Furthermore, indigestible NDF has been described as a baseline of ruminal fill that constrains possible NDF flux; as such, a minimum pool is required for proper rumen function, but exceeding an upper threshold may limit voluntary intake (Grant, 2015). As a result of this emphasis, the accuracy and precision of NDFD determined after short or long time intervals is of considerable research and industry interest, as is the relative consistency of results generated from in situ, STD, or Ankom techniques, as well as assessment of the potential various procedural options within each methodology type. Past attempts to address these issues have included (1) assessment of vessel type, sealing, venting, and gassing procedures (Hall and Mertens, 2008); (2) comparisons of fiber-bag type and use of sodium sulfite at long incubation times (Valentine et al., 2019); (3) development of in vitro methods specifically to determine undigested NDF (Raffrenato et al., 2018); (4) evaluation of storage time and temperature for rumen fluid before transfer into the incubation flask (Robinson et al., 1999); (5) priming techniques for rumen fluid to improve precision (Goeser and Combs, 2009; Goeser et al., 2009); (6) comparisons of in situ and various in vitro methods (Spanghero et al., 2010; Trujillo et al., 2010; Bender et al., 2016); and (7) quantification of 2 pools of digestible NDF (fast and slowly digested) with a minimal number of fermentation time points (Raffrenato et al., 2019). Current recommendations for method 3 Ankom procedures (Ankom Technology, 2017) suggest using a 0.25-g sample, but that a $0.50-\mathrm{g}$ sample size is acceptable for a 48-h incubation. Across past studies, both the 0.25-g (Robinson et al., 1999; Spanghero et al., 2010; Valentine et al., 2019) and the 0.50-g (Goeser and Combs, 2009; Goeser et al., 2009; Trujillo et al., 2010; Bender et al., 2016) sample sizes have been used in conjunction with Ankom methodologies. Recent work in our laboratory (Coblentz et al., 2018b) evaluating rate kinetics of triticale forages used $0.30-\mathrm{g}$ samples sealed within fiber bags as a procedural compromise between the 0.25 -g sample size recommended for short incubation times and ensuring that adequate residue remained for good laboratory precision following 144- and 240-h incubations. Other observations internal to our laboratory have raised questions about the potential effects of sample size within sealed fiber bags on subsequent determinations of NDFD by Ankom procedures. Our objectives were 3 -fold: (1) regress NDFD values from 48 triticale forages determined by Ankom procedures using 0.25- (NDFD25) or 0.50-g (NDFD50) sample sizes at multiple endpoints ranging from 12 to $240 \mathrm{~h}$ on concentrations of fiber-related analytes or growth stage; (2) directly compare NDFD25 and NDFD50 values determined by Ankom procedures after 12-, 24-, 30-, 48-, 144-, or 240-h incubations; and (3) compare NDFD25 and NDFD50 values determined by Ankom methods with those determined by STD procedures obtained from a commercial laboratory.

\section{MATERIALS AND METHODS}

\section{Forages}

Triticale forages $(\mathrm{n}=54)$ were harvested across a wide range of growth stages during the spring of 2016 and 2017. A detailed description of all establishment, fertilization, harvest, and sample preparation procedures for these forages has been reported previously (Coblentz et al., 2018a). Cultivars harvested in 2016 and 2017 were Forerunner (Legacy Seeds, Scandinavia, WI) and Trical 815/366 (Byron Seeds LLC, Rockville, 
Table 1. Summary statistics of triticale forages harvested during 2016 and 2017 at Marshfield, Wisconsin

\begin{tabular}{lccccc}
\hline Item & $\mathrm{N}$ & Mean & Median & Maximum & Minimum \\
\hline asNDF om, ${ }^{1} \%$ of DM & 48 & 51.1 & 50.8 & 68.7 & 35.5 \\
ADL, \% of DM & 48 & 2.62 & 2.73 & 4.76 & 0.68 \\
ADL, \% of asNDF $0 m$ & 48 & 4.88 & 5.12 & 8.74 & 1.37 \\
Growth stage $^{2}$ & 48 & 52.6 & 51.3 & 84.0 & 1.90 \\
\hline
\end{tabular}

${ }^{1}$ as NDF om $=$ NDF determined with heat-stable $\alpha$-amylase and sodium sulfite, and then corrected for residual ash.

${ }^{2}$ Stage of growth identified as 20-29, tillering; 30-39, stem elongation; 40-49, booting; 50-59, heading; 60-69, anthesis; 70-79, seed development; and 80-89, seed ripening (Stauss, 1994).

IN) triticale, respectively. Forerunner is described as a tall and stiff variety that exhibits a mid-season maturity, and is facultative with respect to vernalization. Unlike Forerunner, Trical 815/366 has an obligatory requirement for vernalization. From these, a subset (n $=48$ ) was selected on the basis of maximum range and best possible distribution of concentrations of several nutritional analytes, including NDF determined with heat-stable $\alpha$-amylase and sodium sulfite and corrected for residual ash (asNDFom), ADL (\% of DM), and $\mathrm{ADL}(\%$ of as $\mathrm{NDF}$ om). At harvest, forages were assessed for growth stage using a linear model (Stauss, 1994) suitable for serving as an independent regression variable, where tillering $=20-29 ;$ stem elongation $=$ 30-39; booting $=40-49$; heading $=50-59$; anthesis $=$ $60-69$; seed development $=70-79 ;$ and seed ripening $=$ 80-89. Summary statistics of fiber-related nutritional analytes and growth stages for the selected forages appear in Table 1.

\section{Laboratory Procedures (Ankom)}

Fiber. Whole-plant triticale forages were dried to constant weight under forced air $\left(55^{\circ} \mathrm{C}\right)$, and then ground through a 1-mm screen in a Thomas Model 4 Wiley Mill (Thomas Scientific, Swedesboro, NJ). After grinding, samples were sealed in plastic sample bags pending all subsequent analyses of nutritive attributes. Correction to an absolute DM basis was accomplished by drying 1.0-g samples of each forage overnight in a convection oven at $105^{\circ} \mathrm{C}$, thereby establishing a laboratory DM concentration for each ground sample. Concentrations of asNDFom were obtained by digestion in neutral detergent that included heat-stable $\alpha$-amylase and sodium sulfite using the batch procedures outlined for an Ankom $^{200}$ Fiber Analyzer by the manufacturer (Ankom Technology Corp., Macedon, NY). Subsequently, NDF residues were corrected for residual ash by combustion in a muffle furnace at $500^{\circ} \mathrm{C}$ for $6 \mathrm{~h}$. Procedures for determining concentrations of ADL were reported previously (Coblentz et al., 2018a), and included a sequential analysis of NDF, ADF, and ADL using the batch procedures described by Ankom
Technology Corp. For the determination of ADL, heatstable $\alpha$-amylase was included in the NDF analysis procedures, but sodium sulfite was not included because it attacks lignin and therefore should be omitted from any sequential analysis that includes ADL (Van Soest et al., 1991). Concentrations of ADL also were calculated and reported on a percentage-of-as NDFom basis as ADL/ as NDF om $\times 100 \%$.

In Vitro Digestibility of asNDFom. In vitro digestibility of asNDFom (NDFD) was determined with 3 identical Daisy ${ }^{\text {II }}$ Incubator units (Ankom Technology Corp.). Subsamples of each forage ( 0.25 or $0.50 \mathrm{~g}$ ) were heat-sealed within F57 fiber bags (pore size $=25$ $\mu \mathrm{m}$; Ankom Technology Corp.) using an impulse sealer (model \#AIE-200, American International Electric, City of Industry, CA). Before sample placement, empty F57 filter bags were pre-rinsed in acetone, and then airdried per manufacturer instructions. Fiber bags (F57) containing each of the 48 triticale forages $\times 2$ sample sizes $(0.25$ or $0.50 \mathrm{~g})$ were incubated for $12,24,30$, 48,144 , or $240 \mathrm{~h}(\mathrm{n}=576)$ in triplicate using recommended Ankom procedures (Ankom Technology, 2017). To accommodate triplicate NDFD determinations of the 576 factorial combinations of forages, sample sizes, and incubation times, a total of 6 incubation runs were required. As such, several procedures were employed to minimize run-to-run variability, and limit effects of bias between runs on the final results. These procedures included (1) incubation runs were paired (1 with 2, 3 with 4 , and 5 with 6 ), such that each combination of forage, sample size, and incubation time $(\mathrm{n}=576)$ was represented once within a set of paired runs; (2) each incubation jar contained 24 forage samples, plus one standard forage, and one blank; (3) all samples within an incubation jar were terminated after the same incubation interval; (4) 0.25 - and 0.50 -g sample sizes were not co-mingled within the same incubation jar; (5) each of the triplicate determinations of NDFD for the 576 treatment combinations was conducted in a different Daisy ${ }^{\mathrm{II}}$ Incubator unit; (6) each of the triplicate NDFD determinations for each treatment combination was assigned to a different within-unit position (top right, top left, bottom right, or bottom left); and (7) 
an independent thermometer was mounted within each incubator unit to further standardize each incubation at $39^{\circ} \mathrm{C}$ across all incubators.

Two nonlactating Holstein cows served as donors for the rumen fluid used in the inoculum. Procedures for care and maintenance of donor cows were approved by the Research Animal Resources Committee of the University of Wisconsin-Madison (protocol \#A01006). Cows were offered a diet for ad libitum intake composed of (DM basis) alfalfa/grass haylage (30.3\%), corn silage $(26.9 \%)$, chopped hay $(35.9 \%)$, soybean meal $(4.5 \%)$, urea $(1.1 \%)$, and minerals $(1.3 \%)$, which was formulated to include $47.9 \% \mathrm{NDF}, 14.5 \% \mathrm{CP}$, and 1.35 $\mathrm{Mcal} / \mathrm{kg}$ of $\mathrm{NE}_{\mathrm{L}}$. A hand-operated pump was used to siphon rumen fluid from each cow that was fitted with a ruminal cannula. Fluid was pumped directly into prewarmed $\left(39^{\circ} \mathrm{C}\right)$ insulated bottles, and then transported to the laboratory in a chest-type insulated cooler, where it was filtered through 4 layers of cheesecloth. A total of $400 \mathrm{~mL}$ of rumen fluid with approximately equal contributions from both donors were added to each incubation jar containing buffers and samples. The head-space within each incubation jar was purged with $\mathrm{CO}_{2}$ twice. One purge occurred immediately after buffers and sample bags were added to the incubation jars for pre-warming to $39^{\circ} \mathrm{C}$, and the final $\mathrm{CO}_{2}$ purge occurred immediately following addition of the rumen fluid just before final lid placement. Following incubation, fiber bags containing residues of triticale forages were digested in neutral detergent using heat-stable $\alpha$-amylase and sodium sulfite. Residual fiber was dried overnight in a convection oven at $105^{\circ} \mathrm{C}$, weighed, and then placed in a muffle furnace at $500^{\circ} \mathrm{C}$ for $6 \mathrm{~h}$ to allow correction of the residual fiber weight for contaminant ash. The triplicate values for each treatment combination were averaged as multiple within-sample observations to obtain a final value of NDFD.

\section{Laboratory Procedures (University of Wisconsin Soil and Forage Laboratory)}

For purposes of this study, our intention was to maintain as much independence as possible between the Ankom procedures described previously, and adapted STD procedures used commercially by the University of Wisconsin Soil and Forage Laboratory (Marshfield, WI). As such, triticale samples were presented to the Soil and Forage Laboratory in dried $\left(55^{\circ} \mathrm{C}\right)$ and ground (1-mm screen) form within the same storage bags $(\sim 100$ g) used for all Ankom analyses. All other procedures, including determination of laboratory DM and as NDFom concentrations, in vitro incubation procedures, donor cows, and diets, as well as data management, were completely independent of the Ankom procedures described previously. Within this context, concentrations of asNDFom were determined by the methods of Goering and Van Soest (1970), with modifications as described by Mertens (1992); quantification of residual contaminant ash was completed by combustion of insoluble residues (in crucibles) for $2 \mathrm{~h}$ in a muffle furnace at $500^{\circ} \mathrm{C}$. In vitro incubation procedures were based on those described by Goering and Van Soest (1970), with further modifications as discussed by Kruse et al. (2010). Briefly, duplicate 0.5-g samples were incubated for either 30 or $48 \mathrm{~h}$ within $125-\mathrm{mL}$ Erlenmeyer flasks containing rumen fluid, buffer media, plus micro- and macro-minerals, and were purged continuously with $\mathrm{CO}_{2}$, and maintained in a water bath at $39^{\circ} \mathrm{C}$ for the duration of the incubation period. Although each sample was incubated in duplicate, laboratory constraints prohibited duplicate assessment of all samples simultaneously. As such, duplicate determinations of NDFD for the same sample $\times$ incubation time combination were always conducted in independent incubation runs. Rumen fluid was harvested from one nonlactating Holstein cow with a siphoning pump via a ruminal cannula. Fluid was held in pre-warmed insulated flasks during transport to the laboratory, filtered through 3 layers of cheesecloth, and then injected into the incubation flasks. Each day, the donor cow was offered a forage-based diet for ad libitum intake that was similar in composition to that described previously for the Ankom procedures. After the designated 30- or 48-h incubation periods were reached, incubations were terminated by the same procedures described previously for asNDFom (Goering and Van Soest, 1970; Mertens, 1992); specifically, this included digestion of in vitro residues in neutral detergent containing sodium sulfite and heat-stable $\alpha$-amylase, followed by correction for residual ash by combustion at $500^{\circ} \mathrm{C}$ for $2 \mathrm{~h}$. All determinations of NDFD by both Ankom and STD analytical procedures were reported on a percentage of as NDF om basis.

\section{Statistics}

For fiber components (asNDFom and ADL) and growth stage, the mean, standard deviation, median, maximum, and minimum values were calculated with PROC MEANS of SAS (version 9.3, SAS Institute Inc., Cary, NC). Regressions of NDFD25 and NDFD50 determined by Ankom methods on concentrations of as NDFom, ADL (\% of DM), ADL (\% of as NDFom), or growth stage at harvest were conducted with PROC REG of SAS. Linear, quadratic, cubic, and quartic models were considered, but selection of the most appropriate model was based on the greatest possible coefficient of determination $\left(\mathbf{R}^{2}\right)$ coupled with a signifi- 
cant $(P<0.05)$ coefficient for each polynomial term. Intercepts were always retained in the model, irrespective of whether they differed $(P<0.05)$ from 0 . When regression models were linear for both NDFD25 and NDFD50, a test of homogeneity was applied (PROC GLM of SAS) to determine if slopes and intercepts differed $(P<0.05)$ on the basis of sample size. If there was no difference, a combined $(\mathrm{n}=96)$ linear equation was calculated with PROC REG of SAS. Values of NDFD25 and NDFD50 were directly compared with each other by linear regression for each incubation time using PROC REG, where agreement between sample sizes ideally requires slope $=1$ and intercept $=0$. An additional test statement was included with the regression model to test whether the slope differed $(P<0.05)$ from unity. For these regressions, NDFD25 was considered to be the dependent ( $y$-axis) variable. Direct comparisons of NDFD25 and NDFD50 values with STD methods after 30 - and 48 -h incubations were conducted using similar procedures, where NDFD25 and NDFD50 values were considered to be the dependent variable.

\section{RESULTS AND DISCUSSION}

\section{Description of Sample Set}

Triticale samples selected for this study exhibited ranges of 35.5 to $68.7 \%$ for as NDFom, and of 0.68 to $4.76 \%$ of $\mathrm{DM}$ or 1.90 to $8.74 \%$ of as NDFom for ADL (Table 1). Growth stages at harvest ranged from about jointing $($ stage $=29.3)$ to soft-dough $($ stage $=84.0)$, and the mean growth stage across all harvested samples was 52.6, which corresponds to an early-heading stage of development.

\section{Regressions of NDFD on asNDFom, $A D L$, and Growth Stage}

asNDFom. Regressions of NDFD25 and NDFD50 for triticale forages on their concentrations of as NDFom for all incubation times are summarized in Table 2. For the 12-h incubations, data for both sample sizes were best fit to quadratic functions with $\mathrm{R}^{2} \geq$ 0.733. Overall, asNDFom concentration became a less-effective independent variable as incubation times increased, explaining only about half of the variability in the data set for NDFD25 $\left(\mathrm{R}^{2}=0.492\right)$ and NDFD50 $\left(\mathrm{R}^{2}=0.517\right)$ at the extended $240-\mathrm{h}$ incubation interval. The primary reason for this decline in fit is illustrated for the 48-h incubation in Figure 1a. Concentrations of $a s \mathrm{NDF}$ om were diluted or reduced as a function of grain fill, yielding an isolated cluster of NDFD values associated specifically with the soft-dough stage of growth. These NDFD values were lower than might be expected based on the overall trend established by the remainder of the data set, and specifically by comparisons with less-mature samples with similar as NDFom concentrations.

Regressions of NDFD25 and NDFD50 ( $y$-axis) on as NDF om concentrations ( $x$-axis) were distinct for each sample size after 24,30 , and $48 \mathrm{~h}$, based on best-fit models of different polynomial orders at each incubation time. A linear model was selected for each sample size for the 240-h incubation, but these also were distinct from each other, as tests of homogeneity indicated slopes did not differ $(P=0.954)$, but the intercept for NDFD25 was greater than observed for NDFD50 $(P=0.008)$. For the 144 -h incubation, both sample sizes were fit to linear models with similar slopes $(P$ $=0.845)$ and intercepts $(P=0.605)$, which was condensed to a combined $(\mathrm{n}=96)$ linear relationship $(\mathrm{Y}$ $=-0.971 \mathrm{x}-126.0)$ that explained just over half of the variability within the data set $\left(\mathrm{R}^{2}=0.533\right)$. Generally, visual observation of regression relationships at 24, 30, 48 , and $240 \mathrm{~h}$ indicated a consistently greater NDFD25 compared with NDFD50 across the entire range of as NDFom concentrations evaluated.

$A D L$. Generally, relationships between NDFD25 and NDFD50 and concentrations of ADL (Table 3) were improved $\left(\mathrm{R}^{2} \geq 0.742\right)$ relative to those described previously with as NDFom as the independent variable. For 12-, 24-, 30-, and 48-h incubations, all best-fit regression models were linear, where tests of homogeneity indicated slopes did not differ across sample sizes $(P$ $\geq 0.959$ ), but intercepts in each case were greater for NDFD25 $(P \leq 0.033)$. This suggests that for each of these incubation times, NDFD25 values were consistently greater across the entirety of ADL concentrations. For the 144-h incubation, slopes and intercepts did not differ $(P \geq 0.494)$ between NDFD25 and NDFD50 regressions and were combined $(\mathrm{n}=96)$ into a collective linear response $\left(\mathrm{Y}=-8.185 \mathrm{x}+97.9 ; \mathrm{R}^{2}=\right.$ $0.783)$. Best-fit models were higher ordered (quadratic) for the 240-h incubation at the 0.25 -g sample size ( $\mathrm{Y}$ $\left.=-2.766 \mathrm{x}^{2}+6.84 \mathrm{x}+87.2 ; \mathrm{R}^{2}=0.857\right)$, but a simple linear model was selected for the larger sample size $(\mathrm{Y}$ $\left.=-7.736 \mathrm{x}+97.0 ; \mathrm{R}^{2}=0.786\right)$. Improvement in fit by using $\mathrm{ADL}$ as the independent predictor variable, regardless of sample size or incubation time, and as illustrated for the 48-h incubation in Figure 1b, can likely be explained on the basis of the relationship between ADL and plant maturity. Previously, Coblentz et al. (2018a) reported that NDF and ADF concentrations declined in these triticale forages with the onset of grain fill; however, this did not occur for ADL. Similarly, Cherney and Marten (1982) reported sharp reductions in concentrations of ADL within inflorescence during grain fill for a variety of cereal grains, but this could 
not overcome sharp increases in ADL within other plant parts, such as stem, leaf sheath, and leaf blade, when considered on a collective or whole-plant basis. As such, concentrations of ADL represent a more consistently positive relationship with growth stage than occurs for as NDFom.

$A D L$ (\% of asNDFom). Expressing ADL concentrations as a percentage of as NDFom did not improve fits relative to those described previously in which ADL (\% of DM) was used as the independent variable (Table 4 ), and this is illustrated for the 48-h incubation in Figure 1c. Regardless of incubation time and sample size, all regressions were best fit to linear models. For incubations lasting $24,30,48$, or $240 \mathrm{~h}$, regressions for NDFD25 and NDFD50 exhibited similar slopes $(P \geq$ $0.111)$, but intercepts differed $(P<0.001)$ between sample sizes. For 12- and 144-h incubations, tests of homogeneity indicated neither slopes $(P \geq 0.767)$ or intercepts $(P \geq 0.080)$ differed, and combined, collective linear models were established for the 12 -h $(\mathrm{Y}=$ $\left.-3.198 \mathrm{x}+31.2 ; \mathrm{R}^{2}=0.777\right)$ and $144-\mathrm{h}(\mathrm{Y}=-5.356 \mathrm{x}$ $\left.+102.6 ; \mathrm{R}^{2}=0.732\right)$ incubations. As observed for regressions with as NDFom and ADL (\% of DM) as independent variables, values observed for NDFD25 incubations were consistently greater than those for
NDFD50, whenever regressions were distinct between sample sizes.

Growth Stage. Of the 4 independent variables evaluated to explain changes in NDFD, growth stage served as a better independent variable than any of the nutritional analytes $\left(\mathrm{R}^{2} \geq 0.841\right.$; Table 5$)$. The close relationship between NDFD and growth stage has been described previously (Coblentz et al., 2018b); in that study, these relationships were best fit to linear or quadratic models that declined with plant maturity following 24-, 30-, or 48-h incubations, but overall responses were primarily linear in nature, and generally could be described as such on a practical basis. For the current study, the highly linear character of this relationship was corroborated for both sample sizes and at all incubation intervals, although the best-fit models ranged from linear to cubic functions. For the 12-h incubation, both NDFD25 and NDFD50 were fitted to quadratic models that explained about $90 \%$ of the variability in the data sets $\left(\mathrm{R}^{2}=0.888\right.$ and 0.903 , respectively). Linear models were fitted for both sample sizes following 24 -h incubations, but both slopes $(P=$ $0.019)$ and intercepts $(P<0.001)$ differed on the basis of sample size such that greater values of NDFD were observed for the 0.25-g sample size across the entire

Table 2. Regressions of in vitro digestibility of NDF determined with heat-stable $\alpha$-amylase and sodium sulfite and corrected for residual ash (asNDF om; y-axis, \% of as NDF om) on concentrations of asNDFom (x-axis; \% of DM) for triticale forages harvested at different stages of growth during 2016 and 2017 at Marshfield, Wisconsin ${ }^{1}$

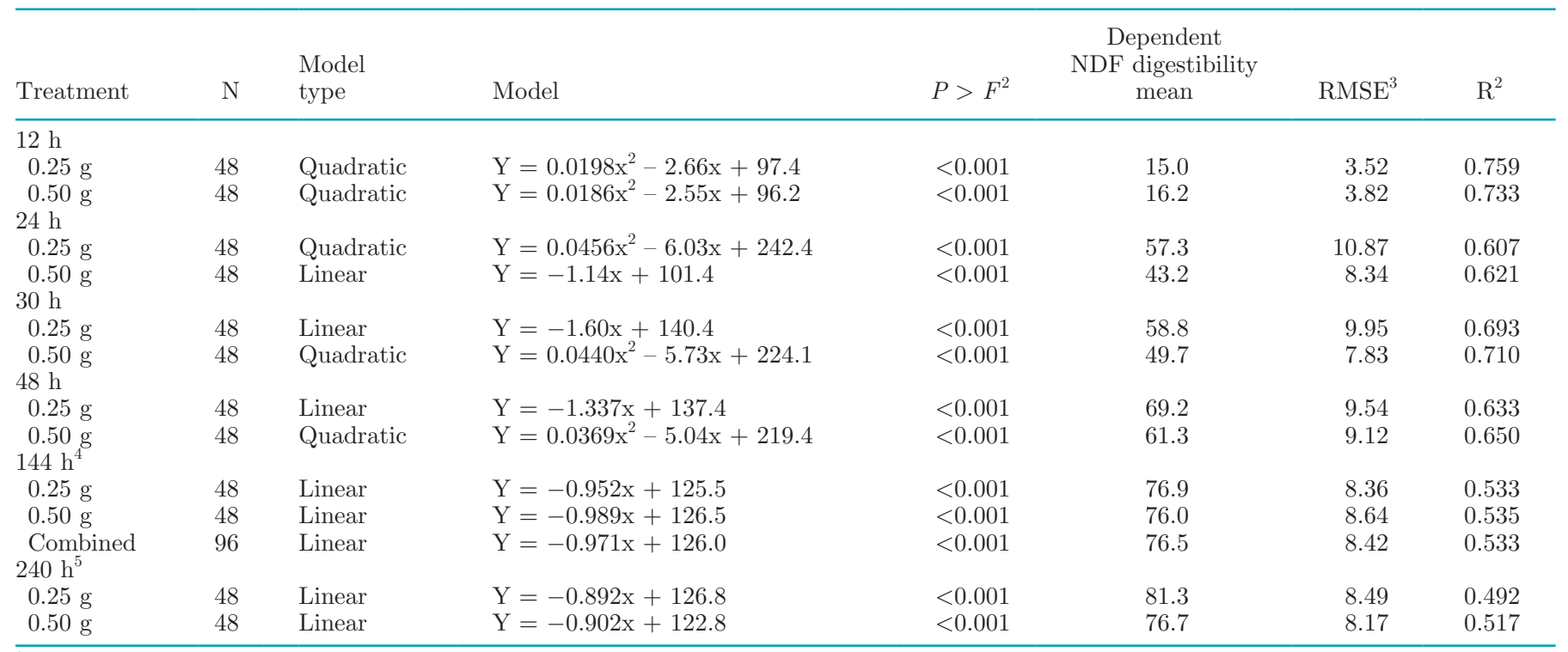

${ }^{1}$ Regressions were conducted for each treatment consisting of in vitro incubations of 0.25 - or 0.50 -g samples for $12,24,30,48,144$, and $240 \mathrm{~h}$, and tests of homogeneity of slopes were conducted whenever both sample sizes yielded linear models.

${ }^{2} P>F$ for the overall regression model; $P \leq 0.05$ indicates the independent variable reliably predicts in vitro digestibility of $a s \mathrm{NDF} o m$.

${ }^{3}$ Root mean square error for regression model.

${ }^{4}$ Tests of homogeneity indicated neither slopes $(P=0.845)$ nor intercepts $(P=0.605)$ differed between 0.25 - and 0.50 -g sample sizes.

${ }^{5}$ Tests of homogeneity indicated slopes did not differ $(P=0.954)$, but intercepts were different $(P=0.008)$ for 0.25 - and 0.50 - $\mathrm{g}$ sample sizes. 
$\bullet 0.25 \mathrm{~g}$

a)

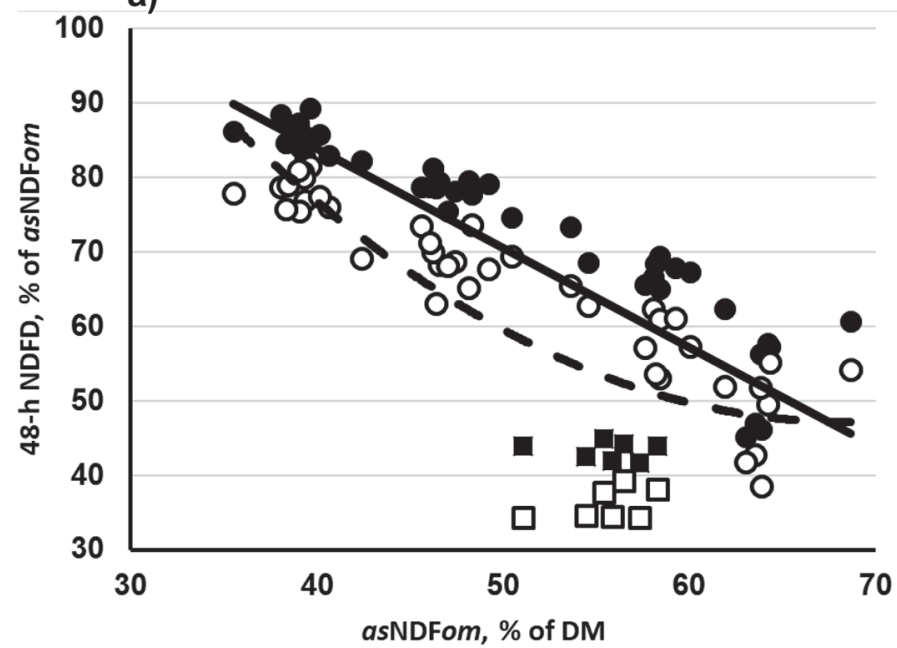

b)

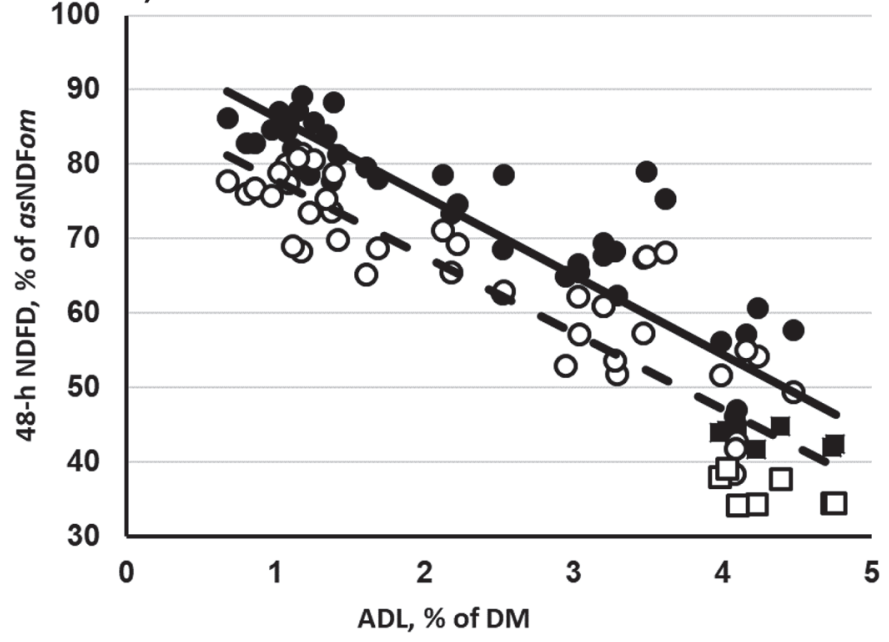

$00.50 \mathrm{~g}$

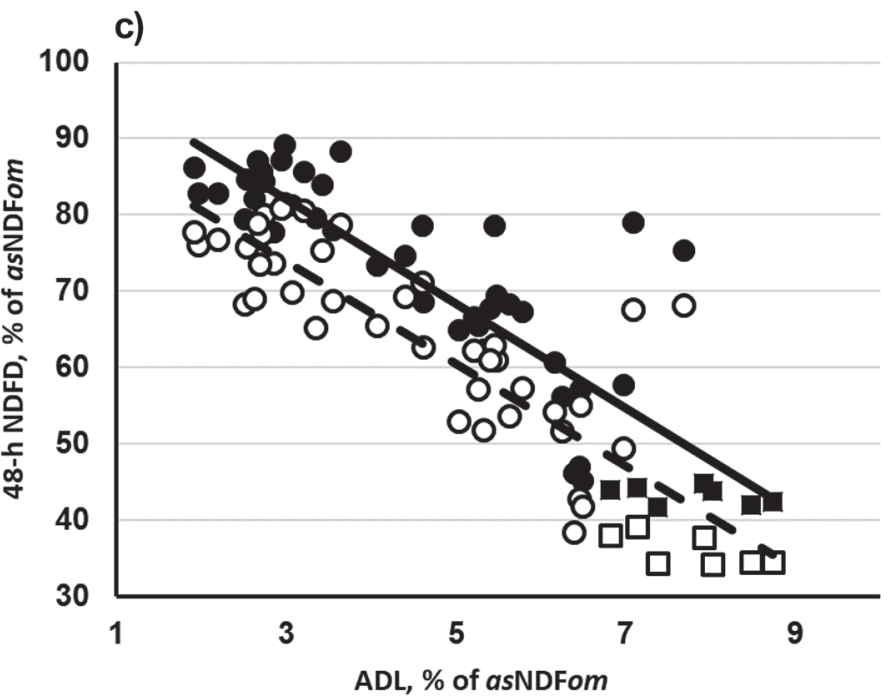

d)

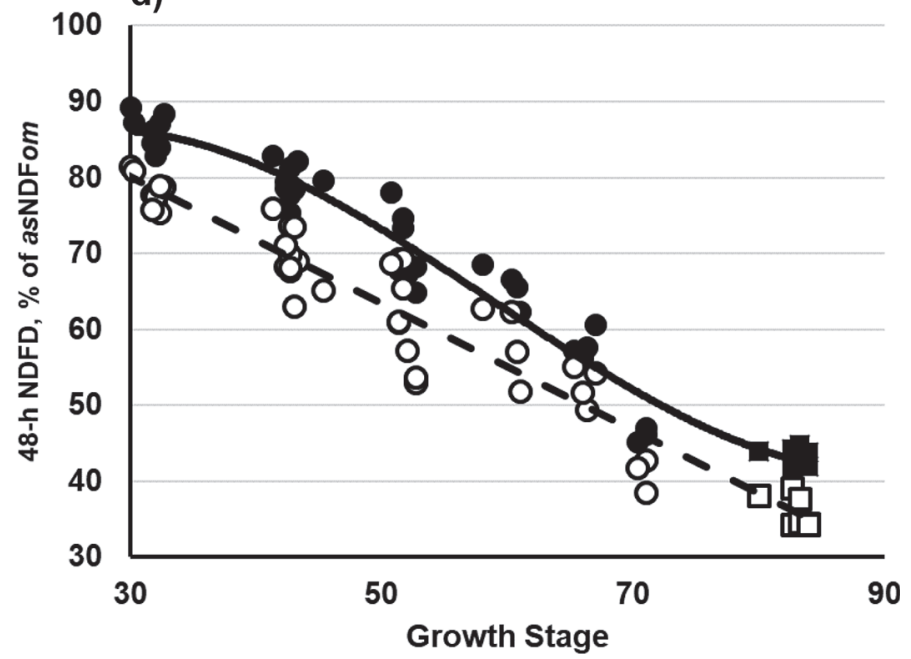

Figure 1. Contrasting relationships between 48-h neutral detergent fiber digestibility (NDFD) and NDF determined with heat-stable $\alpha$-amylase and sodium sulfite and corrected for residual ash (asNDFom; a), ADL (\% of DM; b), ADL (\% of asNDFom; c), or growth stage at harvest (d) for incubations conducted with the Ankom Daisy ${ }^{\mathrm{II}}$ Incubator system (Ankom Technology Corp., Macedon, NY) using sample sizes of 0.25 and $0.50 \mathrm{~g}$ in F57 filter bags. Closed $(\mathbf{\square})$ and open $(\square)$ squares represent triticale forages harvested at the soft-dough stage of growth, and sealed in fiber bags with 0.25 - and 0.50-g sample sizes, respectively. Regression statistics for each curve are provided in Tables 2 to 5.

range of plant maturities. For all other incubation times, best-fit models were distinct for each sample size, exhibiting different polynomial orders. Generally, $\mathrm{R}^{2}$ improved with the length of incubation time, with $\mathrm{R}^{2} \geq 0.946$ for NDFD25 determined after 48- (Figure 1d), 144-, or 240-h incubations, and for NDFD50 after a 144-h incubation.

\section{Direct Relationships Between NDFD Values at 2 Sample Sizes}

Simple linear regressions relating NDFD25 with NDFD50 are summarized for all incubation times in
Table 6, and shown collectively in Figure 2. For sample size to have no effect on determinations of NDFD, any linear regression relating the 2 sample sizes should exhibit a slope and intercept that do not differ from unity and 0 , respectively. For the 12-h incubation, the linear model $\left(\mathrm{Y}=0.933 \mathrm{x}-0.1 ; \mathrm{R}^{2}=0.930\right)$ exhibited a slope that tended to differ from unity $(P=0.084)$, but the intercept did not differ from $0(P=0.843)$. Unlike the 12-h incubation, longer incubations for 24 and $30 \mathrm{~h}$ yielded slopes greater $(P \geq 0.007)$ than unity, reaching 1.186 and 1.206, respectively. As such, this suggests that as forage fiber became more digestible, NDFD25 increased at a significantly faster rate than NDFD50; 
furthermore, for the 24-h incubation, the intercept (6.0) was greater $(P=0.047)$ than 0 , but this did not occur for the 30-h incubation $(P=0.661)$. It remains unclear why the greater values observed for NDFD25 after 24- and 30-h incubations were not observed for the shorter 12-h incubation. However, this may be related to the portion of asNDFom with undefined chemical and physical properties that cannot be accounted for at the intercept within 2- and 3-pool decay models; specifically, this portion of as NDFom is most commonly observed for immature cool-season grasses evaluated by in vitro and in situ procedures, and is generally assumed to be highly digestible (Hoffman et al., 1993; Flores et al., 2007; Coblentz et al., 2018b). Estimates of this undefined fraction have ranged as high as $29.4 \%$ of NDF for timothy (Phleum pretense L.) harvested at the second node stage of growth (Hoffman et al., 1993), but are often $<15 \%$ of NDF and decline with maturity for triticale (Coblentz et al., 2018b). After $48 \mathrm{~h}$ of incubation, the slope relating sample sizes ceased to differ from unity $(P=0.631)$, but the intercept reflected a bias for greater NDFD25 $(P<0.001)$ across the entire range of $\mathrm{NDFD}\left(\mathrm{Y}=1.014 \mathrm{x}+7.1 ; \mathrm{R}^{2}=0.964\right)$.
At extended incubation times (144 and $240 \mathrm{~h}$ ), practical agreement between sample sizes was improved compared with 24-, 30-, and 48-h incubations; however, after $144 \mathrm{~h}$ of incubation, the slope statistically differed $(P=0.027)$ from unity, and the intercept differed $(P$ $=0.006)$ from $0\left(\mathrm{Y}=0.956 \mathrm{x}+4.2 ; \mathrm{R}^{2}=0.982\right)$. After $240 \mathrm{~h}\left(\mathrm{Y}=1.005 \mathrm{x}+4.2 ; \mathrm{R}^{2}=0.983\right)$, the slope could not be distinguished from unity $(P=0.796)$, but the intercept was positive $(P=0.007)$, indicating a small advantage in NDFD25 values relative to the larger sample size. Overall, $\mathrm{R}^{2}$ were improved as incubation time increased from 24 to $240 \mathrm{~h}$ (range $=0.878$ to 0.983 ), thereby indicating that some inherent procedural variability is eliminated by extending incubation times. More importantly, these results suggest faster or greater disappearance (or both) from fiber bags when the smaller 0.25-g sample size is used. This effect was greatest for 24- and 30-h incubations because of the positive slopes $(\geq 1.186)$, but was limited to a more consistent bias for NDFD25 after $48 \mathrm{~h}$ of incubation, based on an intercept (7.1) that suggests a consistent advantage across all triticale forages. Extended incubations (144 or $240 \mathrm{~h}$ ) generally exhibited improved

Table 3. Regressions of in vitro digestibility of NDF determined with heat-stable $\alpha$-amylase and sodium sulfite and corrected for residual ash (as NDFom; y-axis, \% of as NDFom) on concentrations of ADL (x-axis; \% of DM) for triticale forages harvested at different stages of growth during 2016 and 2017 at Marshfield, Wisconsin ${ }^{1}$

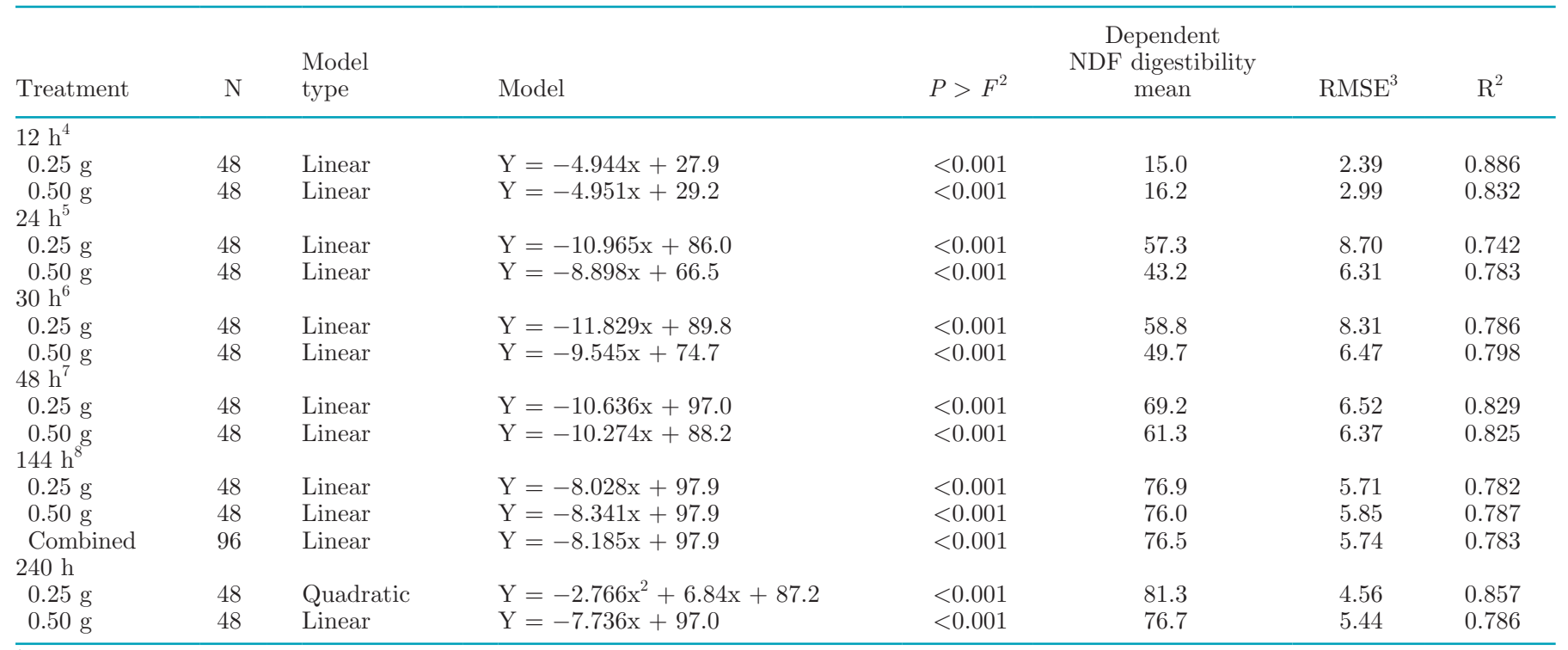

${ }^{1}$ Regressions were conducted for each treatment consisting of in vitro incubations of 0.25 - or 0.50 -g samples for $12,24,30,48,144$, and $240 \mathrm{~h}$, and tests of homogeneity of slopes were conducted whenever both sample sizes yielded linear models.

${ }^{2} P>F$ for the overall regression model; $P \leq 0.05$ indicates the independent variable reliably predicts in vitro digestibility of $a s \mathrm{NDF} o m$.

${ }^{3}$ Root mean square error for regression model.

${ }^{4}$ Tests of homogeneity indicated slopes did not differ $(P=0.959)$, but intercepts were different $(P=0.033)$ for 0.25 - and 0.50 -g sample sizes.

${ }^{5}$ Tests of homogeneity indicated slopes did not differ $(P=0.982)$, but intercepts were different $(P<0.001)$ for 0.25 - and 0.50 -g sample sizes.

${ }^{6}$ Tests of homogeneity indicated slopes did not differ $(P=0.989)$, but intercepts were different $(P=0.001)$ for $0.25-$ and 0.50 -g sample sizes.

${ }^{7}$ Tests of homogeneity indicated slopes did not differ $(P=0.999)$, but intercepts were different $(P=0.003)$ for 0.25 - and 0.50 -g sample sizes.

${ }^{8}$ Tests of homogeneity indicated neither slopes $(P=0.999)$ nor intercepts differed $(P=0.494)$ between 0.25 - and 0.50 -g sample sizes. 
agreement between sample sizes, although there were deviations from predesignated criteria of slope $=1$ and intercept $=0$ that would be required to establish indistinguishable responses across sample sizes.

\section{Comparisons of Our Ankom Results with Those Obtained Commercially Using the Traditional (Sealed-Flask) Methods}

30-h Incubations. Results from 30-h incubations determined by Ankom methodology were related to those determined from STD methods by submitting the same 48 triticale samples to the University of Wisconsin Soil and Forage Laboratory in dried $\left(55^{\circ} \mathrm{C}\right)$ and ground (1-mm screen) form. For 30-h incubations, NDFD25 values exhibited good agreement with STD values obtained with the conventional flask method that used a 0.5-g sample size (Table 7); evidence for this was demonstrated from the linear regression relationship (Y $\left.=1.040 \mathrm{x}-1.8 ; \mathrm{R}^{2}=0.861\right)$, in which the slope did not differ from unity $(P=0.521)$ and the intercept did not differ from $0(P=0.626)$. With the larger sample size restrained in fiber bags, NDFD50 values lagged behind those obtained by STD methods $\left(\mathrm{Y}=0.824 \mathrm{x}+1.6 ; \mathrm{R}^{2}\right.$ $=0.842)$, where the slope was $<1(P=0.002)$. Tests of homogeneity between the NDFD25 and NDFD50 regressions also indicated that slopes and intercepts differed from each other $(P \leq 0.009)$. Taken in total, these data suggest Ankom and STD methods following a 30-h incubation exhibited excellent agreement when the smaller $(0.25-\mathrm{g})$ sample size was restrained within Ankom fiber bags, but when the larger sample size $(0.50 \mathrm{~g})$ was used, the regression relationship between NDFD50 and STD values did not meet the needed condition of slope $=1$ required for acceptable agreement between methodologies.

48-h Incubations. Following a 48-h incubation (Table 7), NDFD25 values again exhibited good agreement with STD values $\left(\mathrm{Y}=1.021 \mathrm{x}-3.4 ; \mathrm{R}^{2}=0.866\right)$, where neither the slope $(P=0.720)$ nor the intercept $(P$ $=0.430)$ differed from unity or 0 , respectively. Unlike the 30-h incubation, the linear regression of NDFD50 values derived from 48 -h incubations on STD values (Y $\left.=0.939 \mathrm{x}-5.5 ; \mathrm{R}^{2}=0.782\right)$ also met the same criteria

Table 4. Regressions of in vitro digestibility of NDF determined with heat-stable $\alpha$-amylase and sodium sulfite and corrected for residual ash (as NDFom; y-axis, \% of as NDFom) on concentrations of ADL (x-axis; \% of asNDFom) for triticale forages harvested at different stages of growth during 2016 and 2017 at Marshfield, Wisconsin ${ }^{1}$

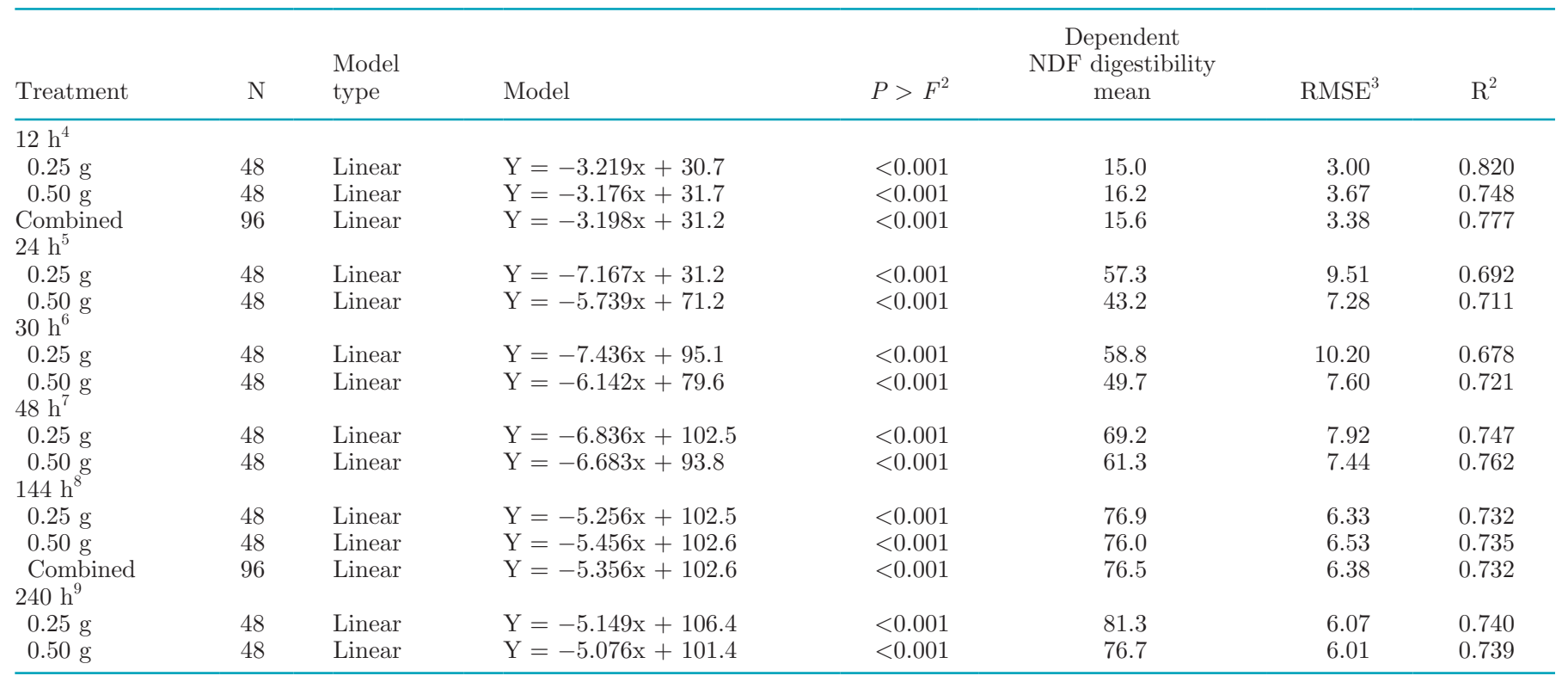

${ }^{1}$ Regressions were conducted for each treatment consisting of in vitro incubations of 0.25 - or 0.50 -g samples for $12,24,30,48,144$, and $240 \mathrm{~h}$, and tests of homogeneity of slopes were conducted whenever both sample sizes yielded linear models.

${ }^{2} P>F$ for the overall regression model; $P \leq 0.05$ indicates the independent variable reliably predicts in vitro digestibility of $a s$ NDF om.

${ }^{3}$ Root mean square error for regression model.

${ }^{4}$ Tests of homogeneity indicated neither slopes $(P=0.902)$ nor intercepts $(P=0.080)$ differed between $0.25-$ and 0.50 -g sample sizes.

${ }^{5}$ Tests of homogeneity indicated slopes did not differ $(P=0.111)$, but intercepts were different $(P<0.001)$ for 0.25 - and 0.50 -g sample sizes.

${ }^{6}$ Tests of homogeneity indicated slopes did not differ $(P=0.173)$, but intercepts were different $(P<0.001)$ for 0.25 - and 0.50 -g sample sizes.

${ }^{7}$ Tests of homogeneity indicated slopes did not differ $(P=0.849)$, but intercepts were different $(P<0.001)$ for 0.25 - and 0.50 -g sample sizes.

${ }^{8}$ Tests of homogeneity indicated neither slopes $(P=0.767)$ nor intercepts $(P=0.495)$ differed between 0.25 - and 0.50 -g sample sizes.

${ }^{9}$ Tests of homogeneity indicated slopes did not differ $(P=0.908)$, but intercepts were different $(P<0.001)$ for 0.25 - and 0.50 -g sample sizes. 
Table 5. Regressions of in vitro digestibility of NDF determined with heat-stable $\alpha$-amylase and sodium sulfite and corrected for residual ash (asNDFom; y-axis, \% of asNDFom) on growth stage at harvest (x-axis; Stauss, 1994 ${ }^{1}$ ) for triticale forages harvested during 2016 and 2017 at Marshfield, Wisconsin ${ }^{2}$

\begin{tabular}{|c|c|c|c|c|c|c|c|}
\hline Treatment & $\mathrm{N}$ & $\begin{array}{l}\text { Model } \\
\text { type }\end{array}$ & Model & $P>F^{3}$ & $\begin{array}{l}\text { Dependent } \\
\text { mean }\end{array}$ & $\mathrm{RMSE}^{4}$ & $\mathrm{R}^{2}$ \\
\hline \multicolumn{8}{|l|}{$12 \mathrm{~h}$} \\
\hline $0.25 \mathrm{~g}$ & 48 & Quadratic & $Y=0.00377 x^{2}-0.795 x+45.3$ & $<0.001$ & 15.0 & 2.39 & 0.888 \\
\hline $\begin{array}{l}24 \mathrm{~h}^{3} \\
0.25 \mathrm{~g}\end{array}$ & 48 & Linear & $Y=-0.887 x+103.9$ & \multicolumn{3}{|c|}{ 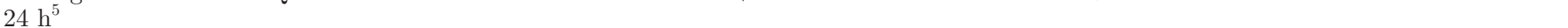 } & 0.841 \\
\hline $0.50 \mathrm{~g}$ & 48 & Linear & $\mathrm{Y}=-0.730 \mathrm{x}+81.7$ & $<0.001$ & 43.2 & 3.99 & 0.913 \\
\hline \multicolumn{8}{|c|}{ - } \\
\hline $0.25 \mathrm{~g}$ & 48 & Cubic & $Y=0.000387 x^{3}-0.0684 x^{2}+2.924 x+49.4$ & $<0.001$ & 69.2 & 2.95 & 0.967 \\
\hline $0.50 \mathrm{~g}$ & 48 & Linear & $\mathrm{Y}=-0.833 \mathrm{x}+105.1$ & $<0.001$ & 61.3 & 3.75 & 0.939 \\
\hline \multicolumn{8}{|l|}{$144 \mathrm{~h}$} \\
\hline $0.25 \mathrm{~g}$ & 48 & Linear & $\mathrm{Y}=-0.671 \mathrm{x}+112.2$ & $<0.001$ & 76.9 & 2.85 & 0.946 \\
\hline $0.50 \mathrm{~g}$ & 48 & Cubic & $\mathrm{Y}=0.000189 \mathrm{x}^{3}-0.0386 \mathrm{x}^{2}+1.748 \mathrm{x}+65.6$ & $<0.001$ & 76.0 & 2.40 & 0.966 \\
\hline \multicolumn{8}{|l|}{$240 \mathrm{~h}$} \\
\hline
\end{tabular}

${ }^{1}$ Stage of growth identified as 20-29, tillering; 30-39, stem elongation; 40-49, booting; 50-59, heading; 60-69, anthesis; 70-79, seed development; and 80-89, seed ripening (Stauss, 1994).

${ }^{2}$ Regressions were conducted for each treatment consisting of in vitro incubations of 0.25 - or 0.50 -g samples for $12,24,30,48,144$, and $240 \mathrm{~h}$, and tests of homogeneity of slopes were conducted whenever both sample sizes yielded linear models.

${ }^{3} P>F$ for the overall regression model; $P \leq 0.05$ indicates the independent variable reliably predicts in vitro digestibility of $a s$ NDFom.

${ }^{4}$ Root mean square error for regression model.

${ }^{5}$ Tests of homogeneity indicated both slopes $(P=0.019)$ and intercepts $(P<0.001)$ differed for 0.25 - and 0.50 -g sample sizes.

$(P \geq 0.305)$. However, tests of homogeneity indicated intercepts were statistically distinct $(P<0.001)$; these results indicate a consistently greater NDFD25 across the entire range of triticale samples and are supported further by a 7.9-percentage unit advantage in the NDFD dependent means for these regressions (69.2 vs. $61.3 \%$ of as NDFom).

Relationships to Other Work. While the effects of the sample size sealed within fiber bags has received limited scrutiny or evaluation, several studies have compared NDFD values determined with Ankom methods to those obtained from other methodologies. Trujillo et al. (2010) compared the NDFD determined from 6 forages and 2 other feedstuffs (brewer's grains and citrus pulp) by in situ and Ankom (0.5-g sample) methods; within that study, NDFD determined with fiber bags placed in the rotating incubation jar system lagged behind ruminal in situ disappearance, especially after 4,8 ,

Table 6. Linear regressions of in vitro disappearance of NDF determined with heat-stable $\alpha$-amylase and sodium sulfite and corrected for residual ash (asNDFom) that relate 0.25 - (y-axis) and 0.50-g (x-axis) samples of triticale forages incubated for 12, 24, 30, 48, 144, or $240 \mathrm{~h}$

\begin{tabular}{|c|c|c|c|c|c|c|c|}
\hline $\begin{array}{l}\text { Incubation } \\
\text { time, h }\end{array}$ & $\mathrm{N}$ & Model $^{1}$ & $\mathrm{RMSE}^{2}$ & $\mathrm{R}^{2}$ & \multicolumn{2}{|c|}{$P>F^{3}$} & $\begin{array}{c}P>|t|^{4} \\
\text { Ho: intercept }=0^{7}\end{array}$ \\
\hline 12 & 48 & $\mathrm{Y}=0.933 \mathrm{x}-0.1$ & 1.87 & 0.930 & $<0.001$ & 0.084 & 0.843 \\
\hline 30 & 48 & $\mathrm{Y}=1.206 \mathrm{x}-1.1$ & 4.67 & 0.933 & $<0.001$ & $<0.001$ & 0.661 \\
\hline 48 & 48 & $\mathrm{Y}=1.014 \mathrm{x}+7.1$ & 3.01 & 0.964 & $<0.001$ & 0.631 & $<0.001$ \\
\hline 144 & 48 & $\mathrm{Y}=0.956 \mathrm{x}+4.2$ & 1.65 & 0.982 & $<0.001$ & 0.027 & 0.006 \\
\hline
\end{tabular}

${ }^{1}$ Units for each dependent and independent regression variable expressed as \% of asNDFom.

${ }^{2} \mathrm{RMSE}=$ root mean square error.

${ }^{3} P>F$, where for tests of slope $=0$ and slope $=1, P \leq 0.05$ indicates rejection of test hypothesis (slope differs from 0 or 1 , respectively).

${ }^{4} P>|t|, P \leq 0.05$ indicates rejection of test hypothesis (intercept differs from 0 ).

${ }^{5}$ Test of hypothesis: slope $=0$.

${ }^{6}$ Test of hypothesis: slope $=1$.

${ }^{7}$ Tests of hypothesis: intercept $=0$. 
or $24 \mathrm{~h}$ of incubation. Although agreement across methods was improved with longer incubation times, in situ determinations of NDFD generally continued to exceed those obtained from Ankom procedures throughout all time intervals, the maximum of which was $96 \mathrm{~h}$. After calculations of disappearance kinetics, these observations further resulted in slower rates of NDF disappearance and longer lag times for many feedstuffs by Ankom methods. Similarly, Spanghero et al. (2010) related in situ determinations of NDFD for 10 feedstuffs to those determined by Ankom methods (0.25-g sample) by linear regression. For a 30 -h incubation, the slope (0.94) did deviate substantially from unity, but the intercept (11.3 percentage units of NDF) indicated consistently greater NDFD across all feedstuffs by in situ procedures. With a longer 48-h incubation, the slope (0.96) was slightly improved relative to the goal of unity, but the intercept (7.3 percentage units of NDF) continued to indicate a consistent bias across all feedstuffs in favor of greater NDFD by in situ procedures. Trujillo et al.
(2010) has suggested that greater NDFD estimates obtained with in situ procedures, particularly at extended incubation times, may be related to a sustained supply of nutrients within the rumen environment, and that better agreement between methods might be achieved through improved inoculum preparation, such as the priming techniques described by Goeser et al. (2009) and Goeser and Combs (2009).

For extended incubation times, Bender et al. (2016) compared undigested NDF at 120 or $288 \mathrm{~h}$ of incubation by both Ankom and in situ methods, in which 13 corn silage samples $(0.5 \mathrm{~g})$ were sealed with F57 fiber bags as a component of both methodologies. The smallest percentage of undigested NDF (greatest NDFD) was attained by in situ procedures with a 288 -h ruminal incubation, whereas the greatest undigested NDF was observed with Ankom procedures after a 120-h incubation; other treatment combinations yielded intermediate values. In comparisons of undigested fiber for 24 forages by Ankom and conventional flask methods,

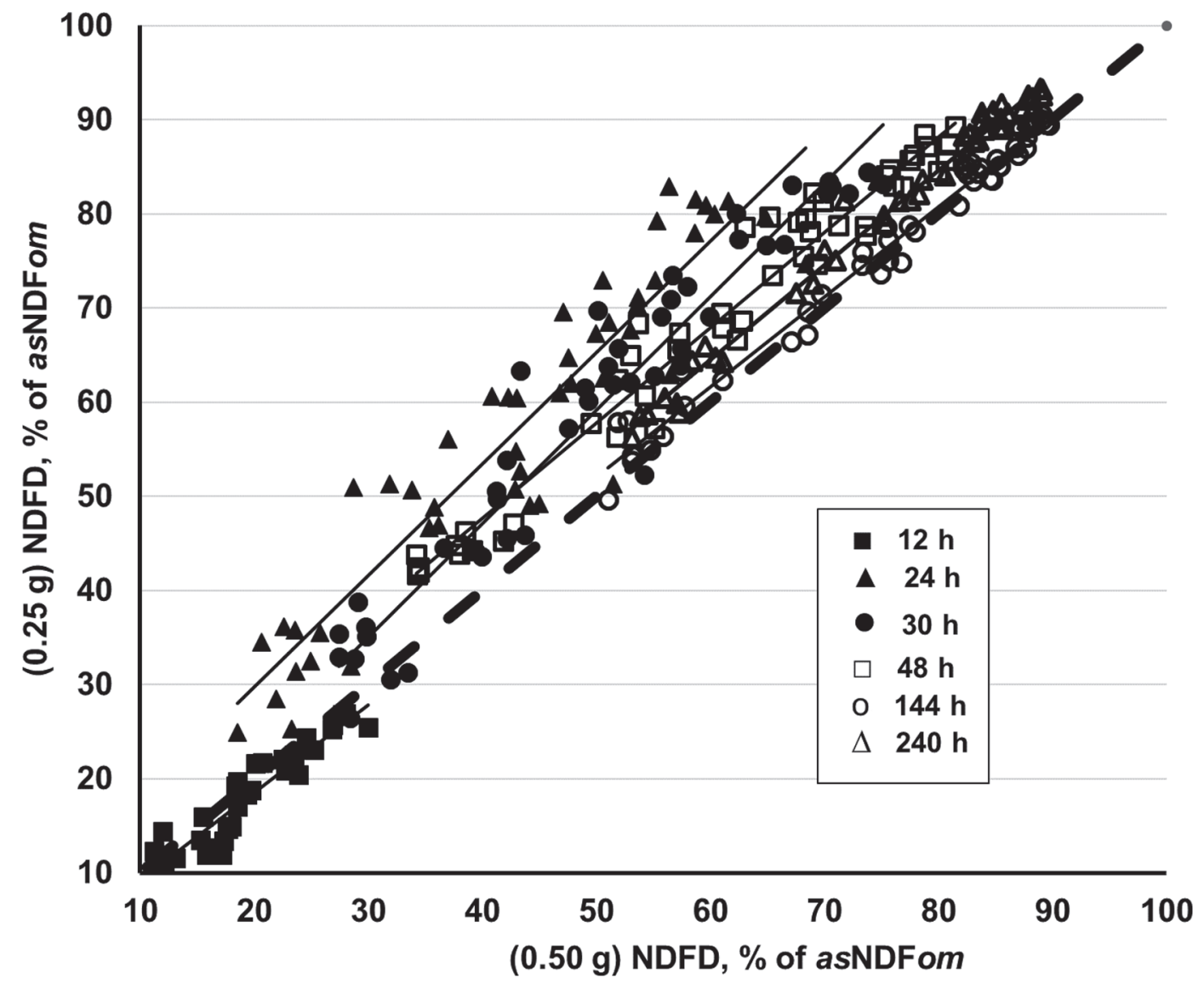

Figure 2. Comparisons of in vitro disappearance of NDF (NDFD) determined with heat-stable $\alpha$-amylase and sodium sulfite and corrected for residual ash (asNDFom) from Ankom F57 filter bags (Ankom Technology Corp., Macedon, NY) with 0.25- or 0.50-g sample sizes at various incubation times. Regression statistics are found in Table $6 ; \mathrm{y}=\mathrm{x}$ is depicted by the bold dashed line. 


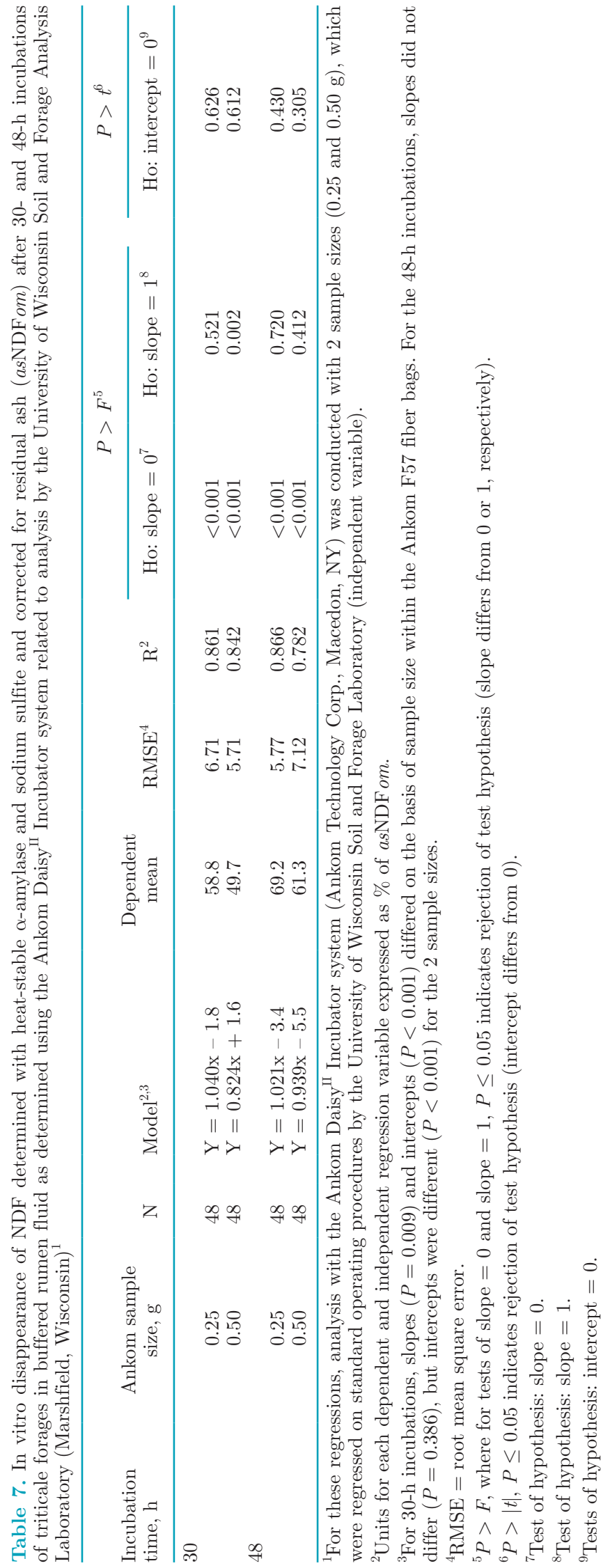

Valentine et al. (2019) found numerically greater undigested NDF at 30-, 120-, and 240-h incubation times for the conventional flask methods, but differences were statistically significant only for the 240-h incubation. In that study, a $0.25 \mathrm{-g}$ sample size was sealed in F57 fiber bags during execution of Ankom procedures that included use of sodium sulfite. Although it is somewhat difficult to directly relate the findings of the present study to past work, most studies comparing alternate methods to Ankom procedures conducted with $\geq 0.50 \mathrm{~g}$ of sample sealed within F57 fiber bags have consistently produced greater NDFD values by the alternative methods across varied incubation endpoints. The close agreement between flask and Ankom methods noted by Valentine et al. (2019) at 30-, 120-, and 240-h endpoints using 0.25-g samples in F57 fiber bags is not direct corroboration, but is tangentially supportive of our results.

\section{CONCLUSIONS}

For the 48 triticale samples selected for this evaluation, plant growth stage at harvest proved to be a far better predictor variable for NDFD than various fiber-related nutritional analytes; this occurred in part because growth stage is not affected by the physiological process of grain fill, whereas concentrations of nutritional analytes (particularly as NDFom) are diluted by this process. Comparisons of $0.25-$ and $0.50-\mathrm{g}$ sample sizes sealed within Ankom fiber bags indicated that greater in vitro fiber digestibility occurred from $0.25 \mathrm{-g}$ samples than $0.50-\mathrm{g}$ samples, especially after $24-$, 30-, and 48 -h incubations. For the 24- and 30-h incubations, the discrepancies between sample sizes were exacerbated as fiber became more digestible. By comparison, agreement between sample sizes was much improved with 12-h, as well as extended (144- and 240-h) incubations. Comparisons of results from 2 different laboratories using Ankom and STD procedures suggest that the best agreement for 24-, 30-, and 48-h incubations occurs when 0.25 -g samples are sealed within fiber bags, but these efforts need to be expanded to a broader array of forage species before broad-based recommendations can be finalized.

\section{ACKNOWLEDGMENTS}

Mention of trade names or commercial products in this article is solely for the purpose of providing specific information, and does not imply either recommendation or endorsement by the U.S. Department of Agriculture. The USDA is an equal opportunity provider and employer. Project supported by appropriated USDA-ARS CRIS funds (\#5090-12630-005-00D). 


\section{REFERENCES}

Ankom Technology. 2017. In vitro true digestibility using the DAISY ${ }^{\mathrm{II}}$ incubator. Ankom Technology Corp., Macedon, NY. Accessed Feb. 3, 2019. https://www.ankom.com/sites/default/files/document -files/Method 3 Invitro_D200_D200I.pdf.

Bender, R. W., D. E. Cook, and D. K. Combs. 2016. Comparison of in situ versus in vitro methods of fiber digestion at 120 and 288 hours to quantify the indigestible neutral detergent fiber fraction of corn silage samples. J. Dairy Sci. 99:5394-5400.

Cherney, J. H., and G. C. Marten. 1982. Small grain crop forage potential: II. Interrelationships among biological, chemical, morphological, and anatomical determinants of quality. Crop Sci. 22:240-245.

Coblentz, W. K., M. S. Akins, K. F. Kalscheur, G. E. Brink, and J. S. Cavadini. 2018a. Effects of growth stage and growing degree day accumulations on triticale forages: 1) Dry matter yield, nutritive value, and in vitro dry matter disappearance. J. Dairy Sci. 101:8965-8985.

Coblentz, W. K., M. S. Akins, K. F. Kalscheur, G. E. Brink, and J. S. Cavadini. 2018b. Effects of growth stage and growing degree day accumulations on triticale forages: 2) In vitro disappearance of neutral detergent fiber. J. Dairy Sci. 101:8986-9003.

Flores, R., W. K. Coblentz, R. K. Ogden, K. P. Coffey, M. L. Looper, C. P. West, and C. F. Rosenkrans Jr. 2007. Effects of fescue type and sampling date on the ruminal disappearance kinetics of autumn-stockpiled tall fescue. J. Dairy Sci. 90:2883-2896.

Goering, H. K., and P. J. Van Soest. 1970. Forage fiber analysis (apparatus, reagents, procedures, and some applications). No. 387-598. USDA-ARS, Washington, DC.

Goeser, J. P., and D. K. Combs. 2009. An alternative method to assess 24-h ruminal in vitro neutral detergent fiber digestibility. J. Dairy Sci. 92:3833-3841.

Goeser, J. P., P. C. Hoffman, and D. K. Combs. 2009. Modification of a rumen fluid priming technique for measuring in vitro neutral detergent fiber digestibility. J. Dairy Sci. 92:3842-3848.

Grant, R. 2015. Making milk with forage: Understanding rumen fiber dynamics. Pages 63-69 in Proceedings of Four-State Dairy Nutrition and Management Conference. June 10-11, 2015. Dubuque, IA.

Hall, M. B., and D. R. Mertens. 2008. In vitro fermentation vessel type and method alter fiber digestibility estimates. J. Dairy Sci. 91:301-307.

Hoffman, P. C., S. J. Sievert, R. D. Shaver, D. A. Welch, and D. K. Combs. 1993. In situ dry matter, protein, and fiber degradation of perennial forages. J. Dairy Sci. 76:2632-2643.

Holden, L. A. 1999. Comparison of methods of in vitro dry matter digestibility for ten feeds. J. Dairy Sci. 82:1791-1794.

Kruse, K. A., D. K. Combs, N. M. Esser, W. K. Coblentz, and P. C. Hoffman. 2010. Evaluation of potential carryover effects associated with limit feeding gravid Holstein heifers. J. Dairy Sci. 93:5374-5384.

Mertens, D. R. 1992. Critical conditions in determining detergent fibers. Page C-1 in Proc. Natl. Forage Testing Assoc. Forage Anal. Workshop, Denver, CO. Natl. Forage Testing Assoc., Omaha, NE.
Mertens, D. R. 2016. Using uNDF to predict dairy cow performance and design rations. Pages 12-19 in Proceedings of Four-State Dairy Nutrition and Management Conference. June 15-16, 2016. Dubuque, IA.

Raffrenato, E., C. F. Nicholson, and M. E. Van Amburgh. 2019. Development of a mathematical model to predict pool sizes and rates of digestion of 2 pools of digestible neutral detergent fiber and a undigested neutral detergent fiber fraction within various forages. J. Dairy Sci. 102:351-364.

Raffrenato, E., D. A. Ross, and M. E. Van Amburgh. 2018. Development of an in vitro method to determine rumen undigested aNDFom for use in feed evaluation. J. Dairy Sci. 101:9888-9900.

Raffrenato, E., and M. E. Van Amburgh. 2010. Development of a mathematical model to predict sizes and rates of digestion of a fast and slow degrading pool and the indigestible NDF fraction. Pages 52-65 in Proceedings of the Cornell Nutrition Conference for Feed Manufacturers. October 19-21, 2010. East Syracuse, NY.

Ricci, P., A. J. Romera, J. C. Burges, H. H. Fernandez, and C. A. Cangiano. 2009. Case study: precision and accuracy of methodologies for estimating in vitro digestibility of Thinopyrum ponticum (tall wheatgrass) hay and haylage fed to beef cattle. Prof. Anim. Sci. 25:625-632.

Robinson, P. H., M. Campbell Matthews, and J. G. Fadel. 1999. Influence of storage time and temperature on in vitro digestion of neutral detergent fibre at $48 \mathrm{~h}$, and comparison to $48 \mathrm{~h}$ in sacco neutral detergent fibre digestion. Anim. Feed Sci. Technol. 80:257266

Spanghero, M., P. Berzaghi, R. Fortina, F. Masoero, L. Rapetti, C. Zanfi, S. Tassone, A. Gallo, S. Colombini, and J. C. Ferlito. 2010. Technical note: precision and accuracy of in vitro digestion of neutral detergent fiber and predicted net energy of lactation content of fibrous feeds. J. Dairy Sci. 93:4855-4859.

Stauss, R. 1994. Compendium of growth stage identification keys for mono- and dicotyledonous plants. Extended $\mathrm{BBCH}$ scale. Compiled by Reinhold Stauss. Ciba-Geigy AG, Basel, Switzerland.

Tilley, J. M. A., and R. A. Terry. 1963. A two-stage technique for the in vitro digestion of forage crops. J. Br. Grassl. Soc. 18:104-111.

Trujillo, A. I., M. de J. Marichal, and M. Carriquiry. 2010. Comparison of dry matter and neutral detergent fibre degradation of fibrous feedstuffs as determined with in situ and in vitro gravimetric procedures. Anim. Feed Sci. Technol. 161:49-57.

Valentine, M. E., E. Karayilanli, J. H. Cherney, and D. J. Cherney. 2019. Comparison of in vitro long digestion methods and digestion rates for diverse forages. Crop Sci. 59:422-435.

Van Soest, P. J., J. B. Robertson, and B. A. Lewis. 1991. Methods for dietary fiber, neutral detergent fiber, and nonstarch polysaccharides in relation to animal nutrition. J. Dairy Sci. 74:3583-3597.

Vogel, K. P., J. F. Pederson, S. D. Masterson, and J. J. Toy. 1999. Evaluation of a filter bag system for NDF, ADF, and IVDMD forage analysis. Crop Sci. 39:276-279.

Wilman, D., and A. Adesogan. 2000. A comparison of filter bag methods with conventional tube methods of determining the in vitro digestibility of forages. Anim. Feed Sci. Technol. 84:33-47. 